\title{
EVASÃO E PERMANÊNCIA DE COTISTAS E NÃO COTISTAS RACIAIS NO ENSINO TÉCNICO
}

\author{
Natalino Neves da Silva \\ Aline de Carvalho Pereira
}

\section{Resumo}

O objetivo desse estudo consiste em analisar o índice de evasão e permanência anual dos estudantes cotistas raciais em comparação com os ingressantes pela ampla concorrência dos cursos técnicos integrados de nível médio, nos anos letivos de 2013 a 2018, em uma instituição federal localizada no Sul de Minas. A abordagem da investigação é de caráter quantitativo e reúne características de pesquisa descritiva e exploratória ao levar em consideração os dados gerados pelo sistema acadêmico, bem como a aplicação de 35 questionários pela Coordenação Pedagógica. Os resultados alcançados revelam que existe uma variação da taxa de evasão e permanência escolar nos três cursos técnicos estudados em relação ao público estudantil de cotistas e não cotistas raciais.

Palavras-chave: cotas raciais; ensino médio profissional; evasão e permanência escolar

\section{EVASION AND PERMANENCY OF S'TUDEN'TS QUO'TAS AND NON- QUOTAS RACIAL IN TECHNICAL EDUCATION}

\begin{abstract}
The objective of this study is to analyze the rate of dropout and annual permanence of the racial quota students in comparison to the participants by the wide competition of the integrated technical courses of average level, in the academic years of 2013 to 2018, in a federal institution located in the Sul de Minas. The research approach is of a quantitative nature and it brings together characteristics of descriptive and exploratory research when taking into account the data generated by the academic system, as well as the application of 35 questionnaires by the Pedagogical Coordination. The results show that there is a variation in the rate of school dropout and permanence in the three technical courses studied in relation to the student population of quotaters and non-quota holders.
\end{abstract}

Keywords: racial quotas; technical education; school evasion and permanency

\section{EVASIÓN Y PERMANENCIA DE COTISTAS Y NO COTISTAS RACIALES EN LA ENSEÑANZA TÉCNICA}

Resumen

El objetivo de este estudio consiste en analizar el índice de evasión y permanencia anual de los estudiantes cotistas raciales en comparación con los ingresantes por la amplia competencia de los cursos técnicos integrados de nivel medio, en los años lectivos de 2013 a 2018, en una institución federal ubicada en el Sul de Minas. El enfoque de la investigación es de carácter cuantitativo y reúne características de investigación descriptiva y exploratoria al tomar en consideración los datos generados por el sistema académico, así como la aplicación de 35 cuestionarios por la Coordinación Pedagógica. Los resultados alcanzados revelan que existe una variación de la tasa de evasión y permanencia escolar en los tres cursos técnicos estudiados en relación al público estudiantil de cotistas y no cotistas raciales.

Palabras clave: cotas raciales; enseñanza media profesional; evasión y permanencia escolar 


\section{CONSIDERAÇÕES INICIAIS}

O presente estudo é resultado de uma investigação, em andamento, que busca entender em um de seus tópicos a evasão e permanência de estudantes ingressantes em uma instituição federal localizada no Sul de Minas de ensino médio técnico. O seu objetivo consiste em analisar o índice de evasão e permanência anual dos estudantes cotistas raciais ${ }^{1}$, em comparação com os discentes ingressantes pela ampla concorrência dos cursos técnicos integrados de nível médio, nos anos letivos de 2013 a 2018, período em que foram implementadas as cotas raciais nessa instituição de ensino, tendo em vista o cumprimento da Lei n. 12.711/2012 2 .

A realização da análise comparada ${ }^{3}$ permite traçar um diagnóstico no sentido de vislumbrar os motivos que os levaram a interromper seus estudos nos cursos técnicos. Assim sendo, as problematizações que nortearam a realização desse estudo foram: entre os anos de 2013 a 2018, qual a taxa de evasão e permanência desse público estudantil nos três cursos técnicos integrados? O percentual verificado é o mesmo entre cotistas e não cotistas raciais? Os cotistas raciais evadem mais nesse nível de ensino?

O procedimento metodológico adotado consistiu no levantamento de documentos, relatórios e formulários disponibilizados pela Coordenação de Registro Escolar e Controle Acadêmico (DRCA) e pela Coordenação Pedagógica, com o intuito de verificar a situação do público estudantil no sistema acadêmico. Com o levantamento realizado foi possível traçar um panorama geral em relação à taxa de evasão e permanência escolar desde a implantação das cotas raciais, nos três cursos técnicos integrados: Mecatrônica, Eletrotécnica e Redes de Computadores.

O método realizado propiciou ainda maior fidedignidade das informações coletadas, tendo em vista as condições de migração interna do sistema acadêmico na unidade (2018-2019), o que possibilitou a matrícula automática de todos os discentes vinculados à instituição. A coleta de dados foi realizada em abril de 2019, por meio do Sistema Integrado de Gestão de Atividades Acadêmicas (SIGAA) possibilitando estimar o número total de evasão e permanência no ano de referência. A utilização desse método possibilitou inclusive fazer uma análise comparada.

As informações extraídas do sistema referem-se: a) o tipo de ingresso na instituição federal (sistema de cotas raciais ou ampla concorrência); b) o curso frequentado; c) o levantamento por autodeclaração por cor / raça, sexo e condição socioeconômica ${ }^{5}$; d) uma análise inferencial sobre os principais motivos de evasão de cotistas e não cotistas raciais.

O número total de estudantes ingressantes foi dividido em duas categorias. A primeira delas diz respeito ao grupo de discentes evadidos que ingressaram nos anos compreendidos entre 2013 a 2018 e permaneceram com as matrículas ativas em curso, ou que concluíram com ou sem a realização do estágio até a data da observação. Ou seja, até o final do ano letivo de 2018.

A segunda categoria refere-se ao grupo daqueles ingressantes que evadiram nos anos anteriores, os quais não apresentavam frequência e notas no ano letivo de 2019. $\mathrm{Na}$ mesma

\footnotetext{
1 A categoria raça é abordada nesse estudo do ponto vista sociocultural, econômico e político. Além disso, optamos por utilizar a expressão "cotistas raciais" haja vista a aplicação das políticas afirmativas destinadas a atingir esse público estudantil.

${ }^{2}$ A referida Lei garante a reserva de $50 \%$ das matrículas por curso e turno nas 59 universidades federais e 38 institutos federais de educação, ciência e tecnologia a estudantes que cursaram integralmente o ensino médio público, sendo que as demais $50 \%$ das vagas são destinadas para ampla concorrência.

${ }^{3}$ É importante ressaltar que o levantamento dos dados partiu de uma iniciativa dos membros da pesquisa, uma vez que a própria instituição de ensino não os possui. Nesse sentido, não foi possível fazer, nesse momento, uma análise estatística comparada longitudinal pormenorizada, para verificar a taxa de evasão e permanência de cotistas e não cotistas raciais, a saber: mesmo ano de referência, ou ao longo dos anos subsequentes.

4 Adotamos a categoria sexo para a realização do estudo.

5 Os dados obtidos revelam que a maior parte dos estudantes cotistas raciais reside com a família. A renda familiar é de até dois salários mínimos.
} 
categoria encontram-se aqueles estudantes que solicitaram transferência para outra instituição pública ou particular, os que se desligaram voluntariamente e os que simplesmente deixaram de frequentar a instituição.

Para análise dos cotistas raciais utilizamos como referência o quantitativo total de estudantes evadidos e permanentes de cada período letivo desde a implantação da política de cotas raciais na instituição, mensurando as informações pelo ano de ingresso de cada estudante.

Fez parte ainda como procedimento de coleta de dados, a aplicação de um questionário eletrônico buscando averiguar as seguintes informações: dados pessoais, trajetória e avaliação da instituição. O questionário foi aplicado via e-mail para os(as) ex-discentes que haviam evadido do curso, bem como para os discentes que procuravam o setor da Coordenação Pedagógica para a solicitação de transferências, trancamentos e cancelamentos de matrícula.

Foram entrevistados 35 estudantes dos três cursos técnicos. De modo geral, a abordagem quantitativa foi privilegiada em relação à análise de todos os dados coletados (BARBETTA, 2007).

Os resultados alcançados revelam que existe uma variação da taxa de evasão e permanência escolar nos três cursos técnicos estudados, nos respectivos anos letivos de 2013 a 2018. Além disso, verificamos que o índice de permanência de estudantes cotistas raciais é maior, comparado aos discentes oriundos da ampla concorrência.

A organização desse artigo está subdividida em duas partes, além dessa introdução e das considerações finais. Na primeira delas, o foco da discussão centra-se em compreender a taxa de evasão e permanência de estudantes cotistas e não cotistas raciais, a partir da análise comparada. Já na segunda, buscamos entender melhor os principais motivos que levam esse público estudantil a evadirem do ensino médio técnico. Nas considerações finais, destacamos o risco de estarmos diante de um cenário de produção de novas desigualdades, as quais se concretizam por meio da evasão escolar, sobretudo de estudantes cotistas raciais.

\section{EVASÃO E PERMANÊNCIA NA EDUCAÇÃO TÉCNICA PROFISSIONAL: UM CAMPO EMERGENTE DE PESQUISA A SER INVESTIGADO}

O tema da evasão e permanência escolar consiste em uma problemática que afeta todos os níveis de ensino, inclusive a educação técnica profissional. A esse respeito, diferentes pesquisas têm-se debruçado em compreender as variáveis endógenas e exógenas envolvidas na produção desse fenômeno (MOREIRA, LAMBERT, CASTRO, 2018; SANTOS, REAL, 2017; BASTOS, GOMES, 2016). Contudo, a evasão e permanência escolar carregam em si fatores multicausais. Historicamente, a implantação de Escolas de Aprendizes e Artífices foi marcada por altos índices de evasão escolar (GRANDO, PADOIN, 2014; RAMOS, 2014; SANTOS, 2000).

No cenário atual, sabe-se que a evasão escolar nos cursos técnicos integrados geram resultados negativos às instituições públicas federais, tais como: a extinção de cursos, a falta de reconhecimento, a redução do quantitativo de formandos em comparação com o número de ingressantes, a ausência de qualificação de jovens para a educação técnica profissional (ARRUDA, 2019).

Para Araújo (2012), não existe um conceito universal para o termo “evasão". Por ser uma temática ampla, seu conceito pode estar atrelado a diferentes significados e interpretações.

Dore e Lüscher (2011, p. 775) compreendem o termo de evasão escolar associado a inúmeros fatores ocorridos tanto no ambiente de ensino quanto fora dele. A evasão escolar tem sido associada, nesse caso, a situações muito diversas. Algumas podem estar relacionadas à retenção e repetência do estudante na escola; à saída da instituição e/ou do sistema de ensino; a não conclusão de um determinado nível de ensino; ao abandono da escola e posterior retorno, entre 
outros. Além disso, sua compreensão abrange ainda indivíduos que nunca ingressaram na escolarização formal, especialmente na educação compulsória.

A definição de evasão escolar adotada aqui, então, aproxima-se da enunciada pelo Ministério da Educação (MEC), como sendo: "[...] a saída definitiva do curso de origem sem conclusão, ou a diferença entre ingressantes e concluintes, após uma geração completa" (BRASIL, 1996, p. 19).

A Associação Nacional dos Dirigentes de Instituições Federais de Ensino Superior (ANDIFES) emprega também o conceito de evasão, adaptando-o para a educação técnica integrada ao nível médio. A partir dele, foram estabelecidas três principais modalidades de evasão: a) evasão do curso ao qual se ingressou: desligamento do curso de nível médio, em razão do abandono, por motivos de não realização da renovação de matrícula, transferência de instituição de ensino, mudança de curso, trancamento ou exclusão por desatendimento a alguma norma institucional; b) evasão da instituição, que se caracteriza pelo desligamento da instituição na qual os estudantes encontravam-se matriculados; c) evasão do sistema, que configura o abandono, definitivo ou temporário, do registro desses estudantes tanto do sistema interno da instituição quanto governamentais (BRASIL, 1996).

A análise dos índices de evasão e permanência da instituição federal de ensino do Sul de Minas, ora realizada, vincula-se ao campo emergente de pesquisa, segundo Dore e Lüscher (2011, p. 778):

No caso brasileiro, à questão da evasão no ensino técnico acrescenta-se a dificuldade de acesso dos jovens a essa modalidade de ensino, tendo em vista os altos índices de evasão e de outros indicadores de fracasso escolar na educação básica. A relação entre a educação básica (ensino fundamental e médio) e a educação técnica é um dos contextos mais significativos da pesquisa sobre evasão na educação técnica no Brasil.

Abandonar ou permanecer no ensino médio técnico está fortemente atrelado, portanto, com as características individuais, fatores sociais, familiares, por especificidades do próprio sistema escolar e pelo grau de atração que outras modalidades de socialização, fora do ambiente escolar, podem exercer sobre a vida do estudante (DORE, LÜSCHER, 2011).

No contexto social pautado por políticas de ações afirmativas ${ }^{6}$, em especial a modalidade de cotas raciais por meio da Lei n. 12.711/2012, torna-se cada vez mais importante identificar os índices de evasão e permanência por modalidades de ingresso, no sentido de realizar uma análise comparada entre o público estudantil alvo dessas políticas e o da ampla concorrência.

Para fins de comparação, distinguimos os respectivos grupos de ingressantes dos três cursos técnicos integrados pelas modalidades: Ampla Concorrência e pelo ingresso através do Sistema de reserva de vagas, sendo elas detalhadas em: Escola Pública e Cor (EP/C), Escola Pública, Renda e Cor (EP/R/C), Escola Pública e Renda (EP/R) e Escola Pública (EP), incluindo o Decreto n. 9.034 vigente em 20 de abril de 2017, que dispõe de reservas de vagas para portadores de deficiência (BRASIL, 2017).

$\mathrm{Na}$ Tabela 1 podemos visualizar a identificação de estudantes evadidos e permanentes por critérios de reserva de vagas e ampla concorrência. Foi possível constatar uma variação entre esse público em relação ao índice de permanência nos cursos técnicos integrados (concluintes,

\footnotetext{
${ }^{6}$ De acordo com o jurista Joaquim Barbosa Gomes (2001, p. 37), as ações afirmativas podem ser definidas como um “[...] conjunto de políticas públicas e privadas de caráter compulsório, facultativo ou voluntário, concebidas com vistas ao combate à discriminação racial, de gênero e de origem nacional, bem como à correção dos efeitos presentes da discriminação praticada no passado, tendo por objetivo a concretização do ideal de efetiva igualdade de acesso a bens fundamentais como a educação e o emprego".
} 
vinculados com/sem estágio curricular e os efetivamente matriculados), entre os períodos letivos de 2013 a 2018.

Tabela 1: Taxa de evasão e permanência estudantil em (\%) anos 2013-2018

\begin{tabular}{|c|c|c|c|c|c|c|}
\hline \multirow[t]{2}{*}{ Ano } & \multirow[t]{2}{*}{ Estudantes } & \multirow[t]{2}{*}{ Ampla } & \multicolumn{4}{|c|}{ Reserva de Vagas } \\
\hline & & & $\mathrm{EP} / \mathrm{C}$ & $\begin{array}{c}\mathbf{E P} / \mathbf{R} / \\
\mathrm{C}\end{array}$ & $\mathrm{EP} / \mathrm{R}$ & EP \\
\hline & & $50 \%(\mathrm{n}=48)$ & \multicolumn{4}{|c|}{$50 \%(n=55)$} \\
\hline \multirow{2}{*}{2018} & Permanentes & 37,5 & 12,7 & 6,4 & 10,9 & 6,4 \\
\hline & Evadidos & 12,5 & 3,6 & 3,6 & 5,5 & 0,9 \\
\hline & & $50 \%(n=53)$ & \multicolumn{4}{|c|}{$50 \%(n=50)$} \\
\hline \multirow{2}{*}{2017} & Permanentes & 18,87 & 10 & 6 & 6 & 4 \\
\hline & Evadidos & 31,13 & 5 & 8 & 6 & 5 \\
\hline & & $50 \%(\mathrm{n}=51)$ & \multicolumn{4}{|c|}{$50 \%(n=53)$} \\
\hline \multirow{2}{*}{2016} & Permanentes & 32,35 & 9,43 & 1,89 & 5,66 & 5,66 \\
\hline & Evadidos & 17,65 & 3,77 & 13,2 & 6,6 & 3,77 \\
\hline & & $50 \%(\mathrm{n}=51)$ & \multicolumn{4}{|c|}{$50 \%(n=50)$} \\
\hline \multirow{2}{*}{2015} & Permanentes & 35,29 & 3 & 7 & 6 & 7 \\
\hline & Evadidos & 14,71 & 10 & 9 & 6 & 2 \\
\hline & & $50 \%(n=51)$ & \multicolumn{4}{|c|}{$50 \%(n=50)$} \\
\hline \multirow{2}{*}{2014} & Permanentes & 24,50 & 9 & 6 & 6 & 5 \\
\hline & Evadidos & 25,49 & 5 & 8 & 6 & 5 \\
\hline & & $50 \%(n=43)$ & \multicolumn{4}{|c|}{$50 \%(n=36)$} \\
\hline \multirow{2}{*}{2013} & Permanentes & 27,91 & 5,6 & 9,7 & 6,9 & 6,9 \\
\hline & Evadidos & 22,09 & 5,6 & 4,2 & 5,6 & 5,6 \\
\hline
\end{tabular}

Fonte: Elaborado pelos autores com dados obtidos do Sistema Integrado de Gestão de Atividades (SIGAA).

Nas modalidades de cotas raciais $(\mathrm{EP} / \mathrm{C}+\mathrm{EP} / \mathrm{R} / \mathrm{C})$, o percentual de permanência foi: 19,1\% (2018), 16\% (2017), 11,32\% (2016), 10\% (2015), 15\% (2014) e 15,3\% (em 2013). Portanto, se agruparmos esses percentuais com o dos demais cotistas (EP/R+EP), constata-se que a permanência de cotistas — 36,4\% (2018), 26\% (2017), 22,64\% (2016), 23\% (2015), 26\% (2014) e 29,1\% (2013) — é maior $(2017,2014$ e 2013) que a de estudantes de ampla concorrência: 37,5\% (2018), 18,87\% (2017), 32,35\% (2016), 35,29\% (2015), 24,5\% (2014) e 27,91\% (2013).

Nesse caso, à revelia da perspectiva feita por alguns pesquisadores(as) (como FRY, MAGGIE, MAIO et. al, 2007) de que cotistas raciais não conseguiram dar conta de acompanhar os estudos ofertados por instituições de ensino de excelência, os dados obtidos parecem problematizar tais previsões revelando, a partir do locus investigado, a permanência significativa desse público na educação técnica.

Em contrapartida, identificamos que os índices de evasão dos cotistas raciais (EP/C+EP/R/C), 7,2\% (2018), 13\% (2017), 16,97\% (2016), 19\% (2015), 13\% (2014) e 9,8\% (2013) somado ao dos demais cotistas (EP/R+EP) - 13,6\% (2018), 24\% (2017), 27,34\% (2016), $27 \%$ (2015), 24\% (2014) e 21\% (2013) —, em comparação com os estudantes de ampla 
concorrência [12,5\% (2018), 31,13\% (2017), 17,65\% (2016), 14,71\% (2015), 25,49\% (2014) e $22,09 \%$ (2013)] são consideravelmente elevados.

A taxa de evasão de estudantes cotistas aconteceu de maneira mais significativa nos anos de 2018, 2016 e 2015. Aprofundando um pouco mais essa análise, em um panorama geral, observamos a tendência de que os estudantes advindos do sistema de cotas apresentam maior permanência em comparação aos de ampla concorrência. Entretanto, os índices de evasão que incidem sobre esse público, principalmente nos períodos assinalados, instigou-nos a entender os motivos que conduzem os discentes a evadirem do ensino técnico.

Nessa perspectiva, analisamos a entrada dos estudantes cotistas raciais matriculados em 2019. Para levantamento das informações, foi levada em consideração a soma em porcentagem dos três cursos técnicos de 100\% ( $\mathrm{n}=66)$ das seguintes modalidades: reserva de vagas, escola pública, renda, cor/raça e escola pública acrescentando os critérios de com ou sem deficiência.

Observando os três anos letivos em que os estudantes cursam o ensino médio integrado, foi considerado, para fins de cálculo, o índice total de repetentes de anos anteriores e o agrupamento dos matriculados nas $1^{\mathrm{a}}, 2^{\mathrm{a}}$ e $3^{\mathrm{a}}$ séries dos três cursos técnicos integrados.

Figura 1: Estudantes cotistas raciais matriculados no período letivo de 2019

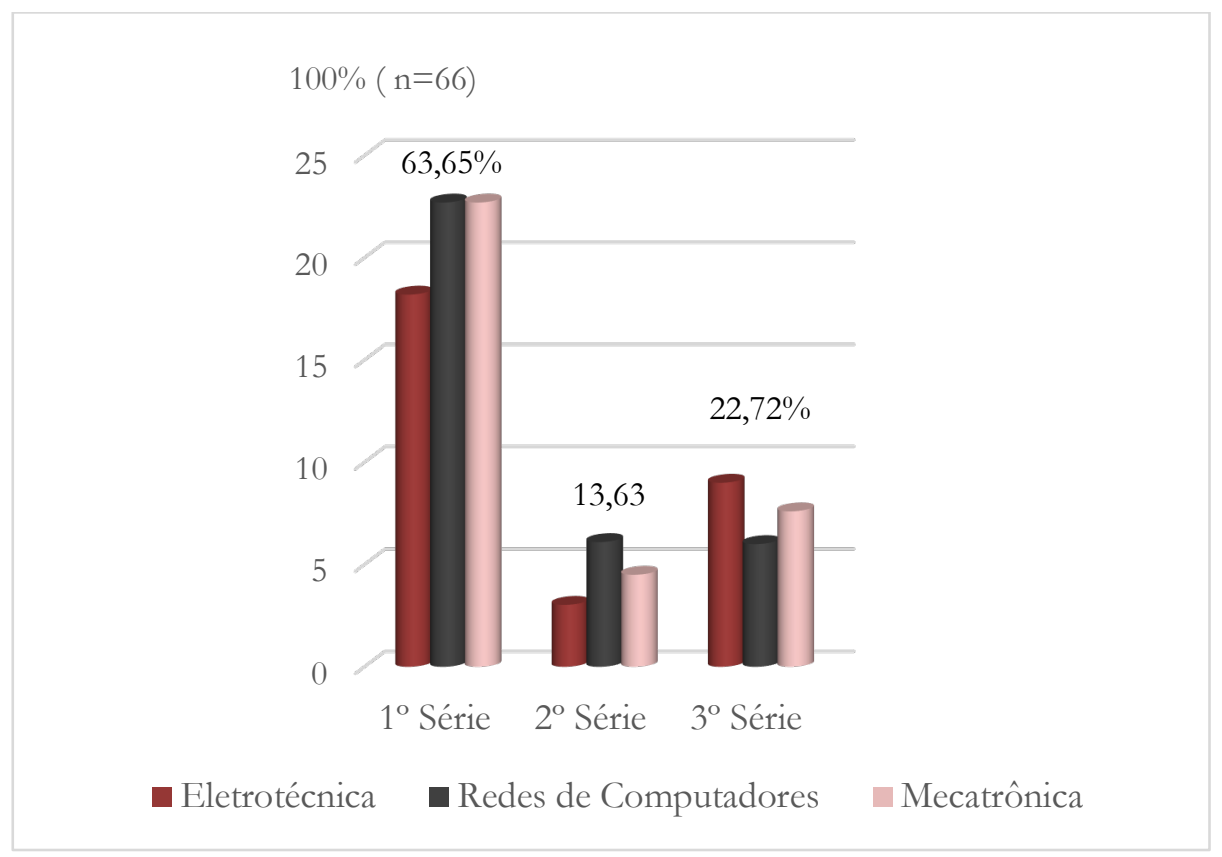

Fonte: Elaborado pelos autores com dados obtidos do Sistema Integrado de Gestão de Atividades (SIGAA).

Os dados obtidos revelam que os percentuais de estudantes cotistas raciais apresentam, no período de 2019, maior índice de permanência em 63,65\%, sobretudo no primeiro ano do curso, comparado com as $2^{\mathrm{a}}$ e $3^{\mathrm{a}}$ séries dos cursos técnicos integrados. Em outras palavras, há uma redução nos anos subsequentes. A taxa é de: 18,2\% $(n=12)$ eletrotécnica; 22,7\% $(n=15)$ redes de computadores; e 22,7\% ( $\mathrm{n}=15)$ mecatrônica.

Isso nos leva a crer que, no início do ano letivo, em cada curso técnico, há ingresso considerável de estudantes cotistas raciais ${ }^{7}$. Contudo, esse processo não se repete na $2^{\mathrm{a}}$ e $3^{\mathrm{a}}$ séries,

\footnotetext{
${ }^{7}$ Cabe ressaltar que estudantes (inclusive cotistas) repetentes podem fazer parte dessa amostra, uma vez que é permitida só uma reprovação consecutiva em cada série.
} 
quando nos deparamos com um percentual global consideravelmente menor de 13,63\% ( $\mathrm{n}=9)$ e $22,72 \%$ ( $n=15)$, o que significa uma redução drástica da representatividade de cotistas raciais.

Em busca de melhor diagnosticar a situação da evasão, realizamos um comparativo nos três cursos, observando os ingressantes por meio de ampla concorrência e de reserva de vagas, a fim de verificar a quantidade de estudantes permanentes e evadidos por sexo.

Foi possível identificar menor índice de evasão entre as mulheres em quase todos os períodos letivos, pelo sistema de reserva de vagas, conforme informações da Tabela 2 . No caso, as taxas de permanência foram: 22,33\% (2018), 13,59\% (2016), 14\% (2014) e 14,10 (2013) sendo que o percentual na modalidade ampla concorrência é de 14,7\% (2017), 17,48\% (2016), 17,95\% (2013). Já no período de 2014, detectamos que houve um expressivo número de evasão das estudantes, tanto pelo sistema de reserva de vagas quanto de ampla concorrência.

Tabela 2: Taxa de evasão e permanência em \% por sexo

\begin{tabular}{|c|c|c|c|c|c|}
\hline \multirow[b]{2}{*}{$\begin{array}{l}\text { Ano de } \\
\text { Ingresso }\end{array}$} & \multirow[b]{2}{*}{ Sexo } & \multicolumn{2}{|c|}{ Permanentes } & \multicolumn{2}{|c|}{ Evadidos } \\
\hline & & $\begin{array}{c}\text { Ampla } \\
\text { Concorrência }\end{array}$ & $\begin{array}{c}\text { Reserva de } \\
\text { Vagas }\end{array}$ & $\begin{array}{c}\text { Ampla } \\
\text { Concorrência }\end{array}$ & $\begin{array}{c}\text { Reserva de } \\
\text { Vagas }\end{array}$ \\
\hline \multirow{2}{*}{$\begin{array}{c}2018 \\
(n=103)\end{array}$} & Fem. & 16,50 & 22,33 & 4,85 & 9,71 \\
\hline & Masc. & 19,42 & 16,50 & 5,83 & 4,85 \\
\hline \multirow{2}{*}{$\begin{array}{c}2017 \\
(n=102)\end{array}$} & Fem. & 14,70 & 10,78 & 13,72 & 8,82 \\
\hline & Masc. & 10,78 & 11,76 & 11,76 & 17,65 \\
\hline \multirow{3}{*}{$\begin{array}{c}2016 \\
(n=103)\end{array}$} & & & & & \\
\hline & Fem. & 17,48 & 13,59 & 9,71 & 11,65 \\
\hline & Masc. & 13,59 & 8,74 & 8,74 & 16,50 \\
\hline \multirow{2}{*}{$\begin{array}{c}2015 \\
(n=101)\end{array}$} & Fem. & 20,79 & 9,90 & 4,95 & 10,89 \\
\hline & Masc. & 14,85 & 13,86 & 9,90 & 14,85 \\
\hline & & & & & \\
\hline \multirow{2}{*}{$\begin{array}{c}2014 \\
(n=100)\end{array}$} & Fem. & 11 & 14 & 15 & 12 \\
\hline & Masc. & 14 & 10 & 10 & 14 \\
\hline \multirow{2}{*}{$\begin{array}{c}2013 \\
(n=78)\end{array}$} & Fem. & 17,95 & 14,10 & 6,4 & 10,26 \\
\hline & Masc. & 11,54 & 11,54 & 17,95 & 10,26 \\
\hline
\end{tabular}

Fonte: Elaborado pelos autores com dados obtidos do Sistema Integrado de Gestão de Atividades (SIGAA)

Essas informações contribuem para verificar que há maior permanência das estudantes do sexo feminino em comparação com os do sexo masculino oriundos do sistema de reserva de vagas. Em se tratando de analisar o perfil do público estudantil da educação técnica e meritocrática isso não é pouca coisa.

Essa constatação tem sido observada também em outras realidades, por meio dos dados do Censo Escolar de 2018, realizado pelo Instituto Nacional de Estudos e Pesquisas Educacionais Anísio Teixeira (Inep), que revelam a expressiva presença e permanência de estudantes mulheres nos cursos profissionais da educação básica (INEP, 2019).

Aprofundando um pouco mais a análise, no sentido de distinguir os meios pelos quais os estudantes de ampla concorrência e cotistas raciais deixaram de frequentar os cursos técnicos 
integrados, e levando-se em consideração o ano de ingresso, pudemos observar que a instituição apresentou elevadas solicitações de transferência em todos os anos analisados.

Figura 2: Evasão do curso entre os anos de 2013 a 2018

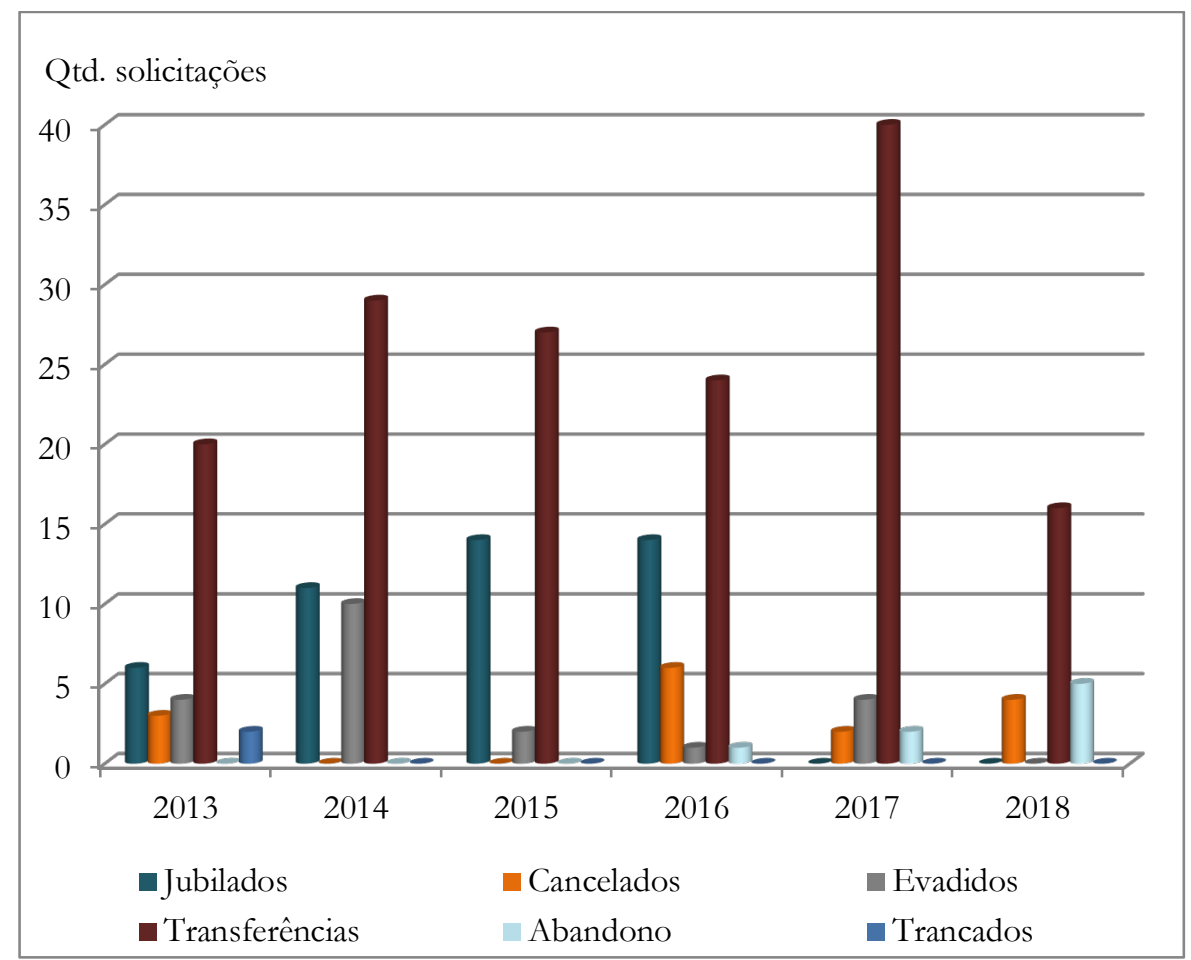

Fonte: Elaborado pelos autores com dados obtidos do Sistema Integrado de Gestão de Atividades (SIGAA)

Uma das hipóteses levantada para a ocorrência dessas transferências diz respeito à oportunidade de eles(as) poderem cursar e concluir o período letivo do ensino médio em outra instituição pública ou particular, sem a necessidade de cursar concomitantemente as disciplinas dos cursos técnicos integrados. O quantitativo em 2017 supera os demais, quando foram contabilizadas 40 transferências no decorrer do período letivo.

Nesse caso, esse dado revelado se aproxima dos resultados obtidos por outras pesquisas como, por exemplo, a que foi realizada pelo Instituto de Pesquisa Econômica Aplicada (IPEA), ao apontar que a maior taxa de evasão (12,7\%) deu-se, segundo o Censo Escolar, entre 2014 e 2015, de estudantes matriculados na $1^{a}$ série do ensino médio. Entre os diversos motivos levantados pela pesquisa, ressalta-se o fator "repetência" no ano inicial desse nível de ensino (IPEA, 2017).

O conhecimento pormenorizado dos principais motivos que induzem o público estudantil cotista racial a evadir do ensino médio técnico se apresentou, então, como sendo uma relevante problematização a ser aprofundada. Para entender o que ocorria, decidimos aplicar um questionário. Afinal de contas, essas informações não estão disponíveis no Sistema Integrado de Gestão de Atividades (SIGAA).

\section{INVESTIGANDO OS PRINCIPAIS MOTIVOS DE EVASÃO DE ESTUDANTES COTISTAS E NÃO COTISTAS RACIAIS}

Foram aplicados 35 questionários aos estudantes cotistas raciais e de ampla concorrência dos três cursos técnicos integrados, com a seguinte pergunta pertinente à realização desse estudo: 
a) quais foram os principais motivos de você não ter concluído o curso. Das 35 pessoas entrevistadas, 19 delas são estudantes ingressantes por ampla concorrência e 16 cotistas raciais.

As principais causas de evasão escolar atribuídas por parte dos cotistas foram: a dificuldade de aprendizagem $(\mathrm{n}=13)$; a falta de tempo em se dedicar aos estudos $(\mathrm{n}=9)$; seguidas do motivo de já haverem sido reprovados anteriormente na instituição, conforme apresentado na Figura 3.

Figura 3: Motivos de evasão de estudantes cotistas e não cotistas raciais

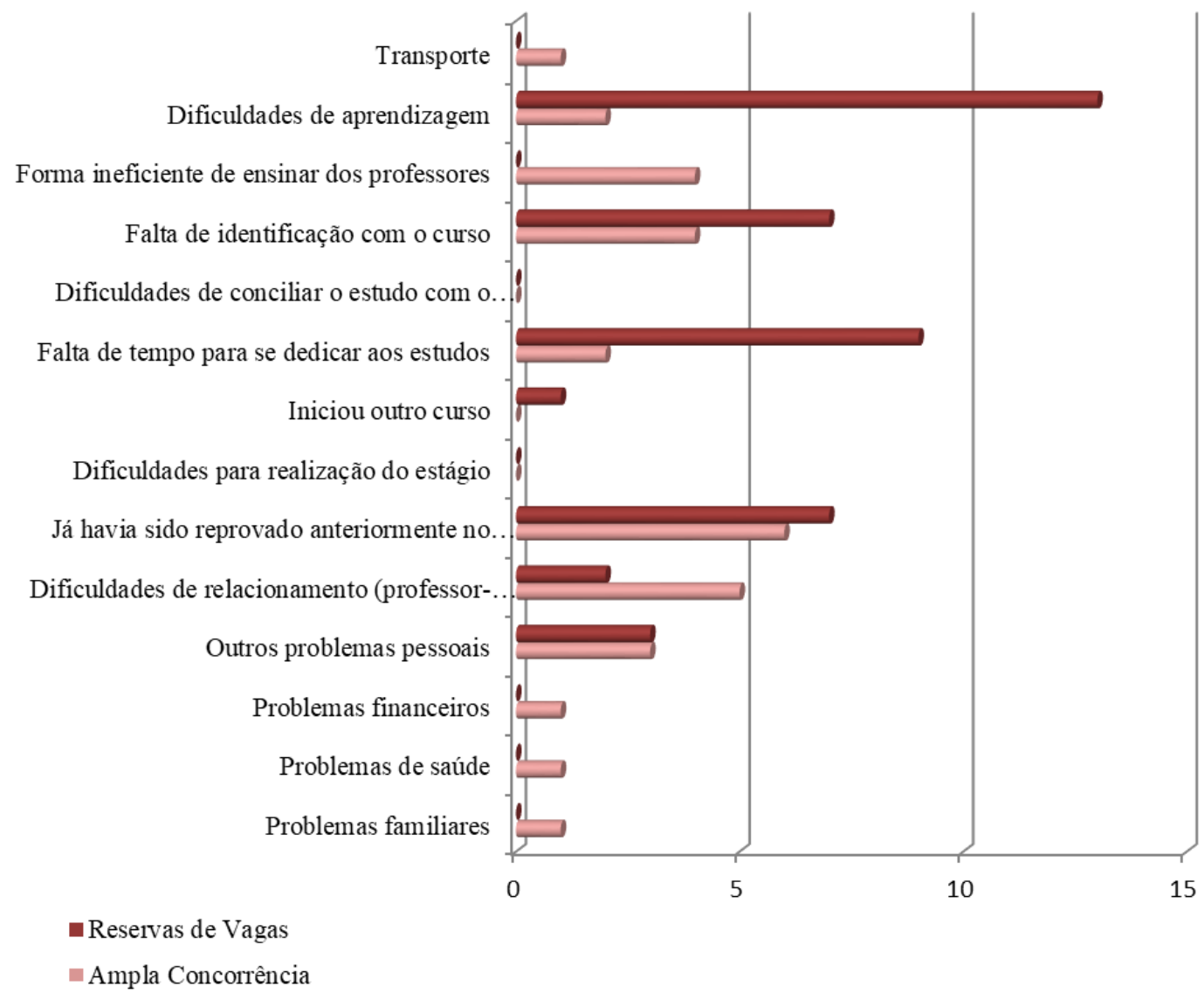

Fonte: Dados obtidos do questionário aplicado pela Coordenação Pedagógica da Instituição

No que concerne aos motivos relacionados "à falta de identificação com o curso", os resultados obtidos aproximam-se do estudo realizado por Grando e Pandoin (2014), os quais demonstram que a evasão no ensino técnico integrado está atrelada à "[...] falta de identificação com a área e dificuldade de aprendizagem" e, além disso, pode estar vinculada, muitas vezes, à precocidade na escolha da profissão, por parte desses estudantes (GRANDO, PANDOIM, 2014, p. 4).

Por conseguinte, um olhar mais detido sobre os dados permite interpretar que o acesso de cotistas raciais por meio de políticas afirmativas significa um importante passo em direção à garantia do direito à educação pública, gratuita e de qualidade. No entanto, nem sempre a presença estudantil negra e as cotas raciais são vistas, nas instituições federais de ensino médio técnico, dessa forma.

Afinal, os expressivos casos de evasão por "dificuldades de aprendizagem” por parte desse público pode estar relacionada com a falta de políticas de permanência na instituição, como 
também a ausência e o silenciamento no trato com a diversidade étnico-racial na educação técnica (FERES JÚNIOR et al., 2017; GUIMARÃES, 2006; MEIRA, 2015; MUNANGA, 2017).

É preciso não perder de vista, nesse sentido, que o racismo no contexto social brasileiro é estrutural. O racismo estrutural pode ser compreendido como uma "[...] decorrência da própria estrutura social, ou seja, do modo 'normal' com que se constituem as relações políticas, econômicas, jurídicas e até familiares, não sendo uma patologia social e nem um desarranjo institucional" (ALMEIDA, 2018, p. 38).

Nessa perspectiva, a motivação de evasão por: "falta de tempo para se dedicar aos estudos" e "já havia sido reprovado anteriormente no curso técnico", por parte dos cotistas raciais revela, em alguma medida, os efeitos de profundas desigualdades socioeconômicas, educacionais e raciais históricas na trajetória escolar desses sujeitos.

Outra séria questão relacionada com os motivos de evasão é aqui então suscitada, uma vez que tanto os estudantes de ampla concorrência quanto os cotistas raciais têm "dificuldades de relacionamento professor-aluno". Essas dificuldades de relacionamento podem interferir diretamente na comunicação entre discentes-docentes, sobre possíveis dificuldades de aprendizagem enfrentadas por serem cotistas raciais nesse nível de ensino. E mais, no processo de constituição identitária étnico-racial positiva nesse ambiente de ensino-aprendizagem.

$\mathrm{Na}$ verdade, consideramos que, se as políticas de ações afirmativas não forem de fato incorporadas pelas instituições federais, acompanhadas também de políticas institucionais complementares de permanência e de promoção da igualdade racial, corre-se o risco de assistirmos passivamente elevados casos de evasão de cotistas raciais. Com isso, o estudo realizado apontou para o risco de estarmos diante de um cenário de produção de novas desigualdades, as quais se concretizam por meio da evasão escolar de discentes que compõem esse segmento.

Essa preocupação tem feito parte de outros estudos como, por exemplo, o que foi realizado por Martins e Ribeiro (2017), ao buscarem analisar o ponto de vista dos estudantes da terceira série do ensino médio integrado dos cursos de Edificações e Mecânica do campus Centro do Instituto Federal de Educação, Ciência e Tecnologia Fluminense (IFF), sobre a política de cotas raciais.

Os achados de pesquisa apontam que o entendimento dos estudantes "[...] refletem a percepção da sociedade brasileira quando o assunto são as ações afirmativas [...], uma vez que desconhecem a política pública e naturalizam a desigualdade étnico-racial, como se esta fosse um subproduto da real desigualdade, que estaria na estrutura de classes" (MARTINS, RIBEIRO, 2017, p. 109).

Nesse sentido, em tempos de implementação de políticas afirmativas voltadas para o público estudantil cotista racial no ensino médio técnico é preciso estar atento sobre as novas formas de produção das desigualdades. Assim sendo, os "[...] fatores associados às características individuais dos alunos e fatores associados com as características institucionais de suas famílias, escolas e comunidades, necessitam ser trabalhados de maneira articulada, com vista a reduzir o fenômeno da evasão de estudantes cotistas raciais nos segundo e terceiro anos". (RUMBERGER, LIM, 2008, p. 67)

É nesse sentido que as instituições federais de ensino técnico têm uma função fundamental a ser desempenhada em relação à efetivação das políticas de ações afirmativas e, consequentemente, da promoção da igualdade racial.

\section{CONSIDERAÇÕES FINAIS}

A análise comparada entre estudantes cotistas raciais e ingressantes pela ampla concorrência revelou que existe uma variação da taxa de evasão e permanência nos três cursos técnicos estudados, nos respectivos anos letivos de 2013 a 2018. 
Verificou-se que o índice de permanência de estudantes cotistas raciais é maior, sobretudo na primeira série do ensino médio, comparado aos discentes oriundos da ampla concorrência. A esse respeito, podemos inferir que existe uma maior predisposição por parte dos cotistas raciais de permanecerem na instituição de ensino médio técnico federal.

Averiguou-se, ainda, menor representatividade desse grupo nas segunda e terceira séries. Em relação a isso, uma possível hipótese de trabalho levantada, em relação à evasão, foi a de que em meio à retenção, ou mesmo diante de um possível jubilamento, muitos estudantes cotistas optam estrategicamente por solicitar sua transferência para outro estabelecimento de ensino.

Uma análise pormenorizada realizada no estudo revela que o ingresso de cotistas raciais não foi seguido de profunda discussão a respeito do significado das políticas afirmativas na educação técnica.

Assim sendo, a permanência estudantil nessas instituições é comprometida, pois para a efetivação de fato das ações afirmativas há necessidade de ser acompanhada por demais políticas institucionais, com foco nas singularidades sócio-raciais e educativas desse novo público.

O estudo revelou a esse respeito que: a) dificuldade de aprendizagem; b) falta de tempo para se dedicar aos estudos; e c) reprovação no curso são os principais motivos que levam à evasão de estudantes cotistas e não cotistas raciais.

Com isso, a pesquisa aponta para o risco de estarmos diante de um cenário de produção de novas desigualdades, as quais se concretizam por meio da evasão escolar por parte de cotistas raciais. Situação essa preocupante por constatarmos, no período de oito anos de existência da Lei n. 12.711/2012, a incipiente realização de pesquisas sobre evasão e permanência de estudantes cotistas raciais na educação técnica, nas instituições federais.

Nesse sentido, esperamos que os resultados aqui alcançados possam, em alguma medida, contribuir, juntamente com os demais estudos realizados, para entender melhor o processo de implementação das políticas afirmativas com o enfoque nesse público estudantil e nesse nível de ensino.

\section{REFERÊNCIAS}

ALMEIDA, Sílvio Luiz de. O que é racismo estrutural? Belo Horizonte: Letramento: Justificando, 2018. (Feminismos Plurais).

ARAÚJO, Elaine de Jesus Melo de. Evasão no PROEJA: estudo das causas no Instituto Federal de Educação, Ciência e Tecnologia do Maranhão/IFMA. 2012. 116f. Dissertação (Mestrado em Educação) - Programa de Pós-Graduação Stricto-Sensu em Educação, Universidade Católica de Brasília, Brasília, 2012. Disponível em https://bdtd.ucb.br:8443/jspui/handle/123456789/682. Acesso em 15 set. 2018.

ARRUDA, Danielle Zanon Marques. Evasão escolar no ensino técnico: um estudo de caso numa escola técnica do Centro Paula Souza. 2019. 137f. Dissertação (Mestrado em Planejamento e Análise de Políticas Públicas) - Faculdade de Ciências Humanas e Sociais, Universidade Estadual Paulista "Júlio de Mesquita Filho". Franca. 2019. Disponível em https://repositorio.unesp.br/handle/11449/181424. Acesso em 10 jun. 2019.

BARBETTA, Pedro Alberto. Estatística aplicada às Ciências Sociais. 7. ed. Florianópolis: Editora UFSC, 2007.

BASTOS, Oliver; GOMES, Carlos Francisco Simões. A evasão escolar no ensino técnico: um estudo de caso do CEFET-RJ. Revista Educação e Cultura Contemporânea, Rio de Janeiro, v. 13, n. 32, p. 217-234, 2016. Disponível em http://periodicos.estacio.br/index.php/reeduc/article/viewArticle/1133. Acesso em 27 out. 2018. 
BRASIL. Decreto n. 9.034, de 20 de abril de 2017. Altera o Decreto n. 7.824, de 11 de outubro de 2012, que regulamenta a Lei n. 12.711, de 29 de agosto de 2012, que dispõe sobre o ingresso nas universidades federais e nas instituições federais de ensino técnico de nível médio. Diário Oficial da União, Brasília, DF, 20 abr. 2017. Disponível em http://www.planalto.gov.br/ccivil 03/ ato2015-2018/2017/decreto/D9034.htm. Acesso em 19 maio 2019.

BRASIL. INEP. Resumo Técnico: Censo da Educação Básica 2018 [recurso eletrônico]. Brasília: Instituto Nacional de Estudos e Pesquisas Educacionais Anísio Teixeira (Inep), 2019. Disponível em

http://portal.inep.gov.br/informacao-da-publicacao/Lasset publisher/6JYIsGMAMkW1/document/id/6386080. Acesso em 25 jun. 2019.

BRASIL. Lei n. 12.711, de 29 de agosto de 2012. Dispõe sobre o ingresso nas universidades federais e nas instituições federais de ensino técnico de nível médio e dá outras providências. Diário Oficial da União, Brasília, DF, 29 ago. 2012. Disponível em http://www.planalto.gov.br/ccivil 03/ ato2011-2014/2012/lei/112711.htm. Acesso em 19 jun. 2018.

BRASIL. Ministério da Educação. Comissão Especial de Estudos sobre a Evasão nas Universidades Públicas Brasileiras - ANDIFES/ABRUEM/SESu/MEC. Diplomação, Retenção e Evasão nos Cursos de Graduação em Instituições de Ensino Superior Públicas. 1996. Disponível em http://www.dominiopublico.gov.br/download/texto/me001613.pdf. Acesso em 11 out. 2018.

DORE, Rosemary; LÜSCHER, Ana Zuleima. Permanência e evasão na educação técnica de nível médio em Minas Gerais. Cadernos de Pesquisa, São Paulo, v. 41, n. 144, p. 772-789, 2011. Disponível em $\quad$ http://www.scielo.br/scielo.php?script=sci abstract\&pid=S010015742011000300007\&lng=en\&nrm=iso\&tlng=pt. Acesso em 13 ago. 2018.

FERES JÚNIOR, João et al. Relatório das desigualdades de raça, gênero e classe. Grupo de Estudos Multidisciplinares da Ação Afirmativa (GEMAA), IESP/UERJ, Rio de Janeiro, n. 1, 2017. Disponível

$\mathrm{em}$ https:/ $/$ www.google.com.br/url?sa $=t \& r c t=j \& q=\& e s r c=s \&$ source $=$ web\&cd $=1 \& c a d=$ rja\&uact $=$ $\underline{\text { 8\&ved=2ahUKEwiikfmSiL7oAhWGIbkGHYivBigQFjAAegQIBBAB\&url=http } \% 3 \mathrm{~A} \% 2 \mathrm{~F} \% 2 \mathrm{Fg}}$ emaa.iesp.uerj.br $\% 2 \mathrm{Fwp}-$ content $\% 2$ Fuploads $\% 2 \mathrm{~F} 2017 \% 2 \mathrm{~F} 08 \% 2 \mathrm{FRelato} \% 25 \mathrm{CC} \% 2581$ rio Corrigido2.0.pdf\&usg=AOvVaw34YS2dELeSvolD8ZjdGIdl. Acesso em 13 jul. 2018.

FRY, Peter; MAGGIE, Yvonne; MAIO, Marcos Chor et al. (orgs.). Divisões perigosas: políticas raciais no Brasil contemporâneo. Rio de Janeiro: Civilização Brasileira, 2007.

GOMES, Joaquim Barbosa. Ação afirmativa \& princípio constitucional da igualdade. Rio de Janeiro: Renovar, 2001.

GRANDO, Paula Cristina; PADOIN, Egre. Um estudo de caso comparativo sobre a permanência e evasão, no ensino médio integrado. In: Seminário de Pesquisa e Extensão: inovação do IFSC, 4., 2014, Gaspar, SC. Anais... Gaspar, Santa Catarina: UFSC, 2014. Disponível em http://www.eventoscientificos.ifsc.edu.br/index.php/sepei/sepei2014/paper/download/672/57 2. Acesso em 23 fev. 2018.

GUIMARÃES, Antônio Sérgio Alfredo. Depois da democracia racial. Tempo Social: Revista de Sociologia da USP, São Paulo, v. 18, n. 2, p. 269-287, 2006. Disponível em www.scielo.br/pdf/ts/v18n2/a14v18n2.pdf. Acesso em 15 mar. 2018.

INSTITUTO DE PESQUISA ECONÔMICA APLICADA (Ipea). Indicadores de Fluxo Escolar da Educação Básica. Brasília, Ipea, 2017. Disponível em 
http://download.inep.gov.br/educacao_basica/censo_escolar/apresentacao/2017/apresentacao indicadores de fluxo escolar da educacao basica.pdf. Acesso em 15 maio 2019.

MARTINS, Ana Carolina; RIBEIRO, Marcos Abrahão. Redistribuição ou reconhecimento? O ponto de vista dos alunos do ensino médio integrado do campus Centro do IFF sobre a política de cotas da Rede Federal de Educação. [Syn]thesis, Rio de Janeiro, v. 10, n. 1, p. 97-110, jan./jun. 2017. Disponível em https://www.e-publicacoes.uerj.br/index.php/synthesis. Acesso em 19 jun. 2018.

MEIRA, Cristiane Araújo. A evasão escolar no ensino técnico profissionalizante: um estudo de caso no campus Cariacica do Instituto Federal do Espírito Santo. 2015. 118f. Dissertação (Mestrado em Gestão Pública) - Centro de Ciências Jurídicas e Econômicas, Universidade Federal do Espírito Santo, Vitória, 2015. Disponível em http://repositorio.ufes.br/handle/10/1562. Acesso em 15 mar. 2018.

MOREIRA, Larici Rocha; LAMBERT, Aline dos Santos; CASTRO, Regina Celi. Educação profissional e tecnológica: permanência e evasão em foco. Rev. Bras. Edu. Saúde, v. 8, n. 4, p. 48-53, out-dez. 2018. Disponível em http://www.gvaa.com.br/revista/index.php/REBES. Acesso em 20 ago. 2019.

MUNANGA, Kabengele. As ambiguidades do racismo à brasileira. In: KON, Noemi Moritz; SILVA, Maria Lúcia da; ABUD, Cristiane Curi. (orgs.). O racismo e o negro no Brasil: questões para a psicanálise. São Paulo: Perspectiva, 2017. p. 33-44.

RAMOS, Marise Nogueira. História e política da educação profissional. Curitiba, Instituto Federal do Paraná, 2014. Disponível em http://curitiba.ifpr.edu.br/wp-content/uploads/2016/05/Históriae-política-da-Educação-profissional.pdf. Acesso em 20 mar. 2017.

RUMBERGER, Russell; LIM, Sun Ah. Why students drop out of school: a review of 25 years of research. Santa Barbara: University of California, 2008.

SANTOS, Jailson Alves dos. A trajetória da educação profissional. In: LOPES, Eliane Marta Teixeira et al. 500 anos de educação no Brasil. 2. ed. Belo Horizonte: Autêntica, 2000. p. 205-224.

SANTOS JÚNIOR, José da Silva; REAL, Gisele Cristina Martins. A evasão na educação superior: o estado da arte das pesquisas no Brasil a partir de 1990. Avaliação, Campinas; Sorocaba, São Paulo, v. 22, n. 2, p. 385-402, jul. 2017. Disponível em http://www.scielo.br/scielo.php?pid=S141440772017000200385\&script=sci abstract\&tlng=pt. Acesso em 20 fev. 2018.

Submetido em marco de 2020

Aprovado em agosto de 2020

\section{Informações dos autores}

Natalino Neves da Silva

Professor Adjunto do Instituto de Ciências Humanas e Letras (ICHL), Departamento Ciências Humanas

(DCH), da Universidade Federal de Alfenas (UNIFAL-MG)

E-mail:professornatalino@gmail.com

ORCID: https://orcid.org/0000-0002-1746-8713

Link Lattes: $\underline{\text { http://lattes.cnpq.br/8701722710780673 }}$ 
Aline de Carvalho Pereira

Servidora Técnico-Administrativa no Setor de Registro e Controle Acadêmico (SRCA) - CEFET-MG, Unidade Nepomuceno

E-mail: alinepereira@ufsj.edu.br

ORCID: https://orcid.org/0000-0002-4545-2372

Link Lattes: http://lattes.cnpq.br/5065261851012464 